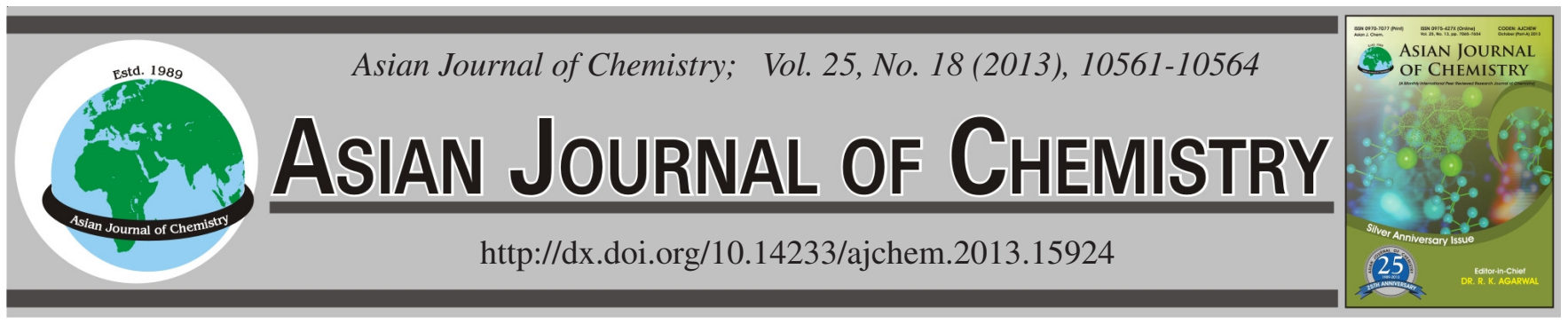

\title{
in vitro Evaluation of Antioxidant Activity of Phytochemical Extracts from Different Varieties of Various Plants
}

\author{
RASHIDA PARVEEN* and NAVEED AKHTAR
}

Department of pharmacy, The Islamia University of Bahawalpur, Bahawalpur, Pakistan

*Corresponding author: E-mail: rashida.pharmacist@gmail.com

\begin{abstract}
In the present study, we examined the comparison of antioxidant activity of six different varieties of three different plants, which were Punica granatum (red and white), Carica papaya (red and yellow) and Lycopersicon esculentum (greenish and red), extracts in different solvents as well as different techniques used for the preparation of plants extracts. We also investigated the secondary metabolites present in different varieties of Punica granatum (red and white), Carica papaya (red and yellow) and Lycopersicon esculentum (greenish and red). The extraction of peel of Punica granatum (red and white) by using $50 \%$ aqueous ethyl alcohol in 1:1 solvent ratio, pulp of $C$ arica papaya (red and yellow) with hexane:ethanol:methanol in 1:1:1 solvent mixture and Lycopersicon esculentum (greenish and red) with hexane:ethanol:acetone in 2:1:1 ratio of solvents. The free radical scavenging activity is determined by using DPPH method and different phytochemical tests were performed to investigate the secondary metabolites. It was resulted that $50 \%$ ethyl alcohol w/v peel extract of Punica granatum extract showed $84 \%$ free radical scavenging activity and the percentage of antioxidant activity Lycopersicon esculentum and Carica papaya extracts were 79 and $73 \%$, respectively. The different phytochemical tests showed that different active secondary metabolites are present in Punica granatum (red and white), Carica papaya (red and yellow) and Lycopersicon esculentum (greenish and red) plant extracts which are necessary for biological process of life.
\end{abstract}

Key Words: Punica granatum, Carica papaya, Lycopersicon esculentum, DPPH, Secondary metabolites.

ᄂ _ - _ - _ - _ - - - - - - - - - - - - - - - - - - - -

\section{INTRODUCTION}

Natural botanical agents have constituents which has beneficial effects to our health. Natural phenolic compounds may be used, not only in food protection, but also as nutraceutical and pharmaceuticals. Different varieties and colour of plants or fruits have variation in antioxidant activity and contents composition. The extractions and measurement of antioxidant activity of various plants extracts that is, Punica granatum (red and white peel), Carica papaya (red and yellow pulp) and Lycopersicon esculentum (greenish and red pulp) extracts were done.

Botanical antioxidants have activity against reactive oxygen species (ROS) mediated photo carcinogenesis and photo aging. Botanical antioxidants have attracted considerable attention because of their skin photo protective effects ${ }^{1}$. The antioxidant activity mechanism was predicted or estimated by capturing free oxygen and chelating metal ions ${ }^{2}$. The food intake of antioxidants compounds is responsible for lowering of health problems ${ }^{3}$. Botanical source antioxidants like ascorbic acid, tocopherol, flavonoids, retinoic acid, arbutin, niacinamide, flavonoids, polyphenols, gingko, ginseng and glucosinolates have been recognized as potential antioxidants ${ }^{4}$.
Pomegranate Punica granatum L. relates to family punicaceae ${ }^{5,6}$. A small shrub type tree is $6 \mathrm{~m}$ high. Anatomically several compartments of Punica granatum tree fruit can be: Seed, juice, peel, leaf, flower, bark and roots. All these part has potent pharmacological properties. Fruit can be divided into three parts: the juice (30\% of fruit weight) and seeds ( $3 \%$ of fruit weight) and the peels with interior network of membranes ${ }^{7}$.

Recent reports also suggest that polyphenol rich pomegranate extract has antioxidant and antiviral properties and improves the effectiveness of topical sunscreens. Pomegranate fruit extract has also recently been identified as an effective photo chemo- preventive agent. A pomegranate extract (PE) from the rind containing $90 \%$ ellagic acid was tested for its skin-whitening effect. Pomegranate extract showed inhibitory activity against mushroom tyrosinase in vitro and the inhibition by the extract was comparable to that of arbutin, which is a known whitening agent ${ }^{8}$.

The chemical constituents of the Punica granatum vary according to variety, cultivation conditions, habitat, environment and ripening of fruit. Punica granatum is the potent source of antioxidants elements compounds including 
flavonoids and hydrolysable tannins which consider $92 \%$ antioxidant activity ${ }^{9}$.

Tomatoes, Lycopersicon esculentum (Solanaceae) are an important source of antioxidant compounds, such as lycopene, phenolic and ascorbic acid ${ }^{10}$. Colour is the first characteristic the consumer perceives of a food and it confers expectations of quality and flavor. The rich source of lycopene is tomatoes ${ }^{11}$. The tomato with a brighter red colour (higher had a higher lycopene content of tomatoes) can be used as an indicator of their lycopene content. The phenolics and flavonoids were significantly related to the antioxidant activity of the hydrophilic extract ${ }^{12}$. Carotenoids are efficient antioxidants capable of scavenging reactive oxygen species generated under conditions of photo oxidative stress. This study was designed to investigate whether intervention with a natural dietary source rich in lycopene protects against UV-induced erythema in humans. The quantification of lycopene content is thus of considerable nutritional interest and is essential for determining the potential health benefits of tomatoes and tomato products $^{13,14}$.

Papaya, Carica papaya (Caricaceae) is a fruit crop widely grown in tropical and sub-tropical environments. The two major papaya fruitflesh colours, red and yellow, are controlled by a single genetic locus with yellow being dominant over red. The fruit flesh colour of papaya is determined largely by the carotenoid content. Red-fleshed papaya fruit contain high levels of lycopene, whereas yellow-fleshed fruit do not. The colour of papaya fruit flesh is determined largely by the presence of carotenoid pigments. Red-fleshed papaya fruit containlycopene, whilst this pigment is absent from yellow-fleshed fruit $^{15}$. Red fleshed papaya contains lycopene which is potent antioxidant and is beneficial for cardiovascular disease and cancer, and also have benefit for protective effects and against oxidative damage ${ }^{16}$. Carica papaya is traditionally used to treat various skin disorders, including wounds. It is widely used in developing countries as an effective and readily available treatment of various wounds particularly burns ${ }^{17}$. This extract is undergoing further investigation for its use as a topical agent in the herbal market. The latex extract contains papain, which is a proteolytic enzyme valuable in clearing epithelial debris in wound healing. It is similar to bromelain found in pineapple. Some dermatologic surgeons are recommending the use of oral bromelain to prevent bruising and speed its resolution after liposuction ${ }^{18}$. The present study was conducted with the main objective of investigating the most potent antioxidant activity of various plants extracts.

Phytochemical evaluation of plant reveals that it contains ethyl acetate methyl heptacosanoate. In addition, heptacosanoate, $\beta$-sitosterol, ursolic acid, gallic acid, luteolin and $\beta$-sitosterol, 3-O- $\beta$-D-glucopyranoside was also detected in various parts of plant and had been isolated from it ${ }^{19}$. Some other researchers have also reported a few new chemical constituents from the plant e.g. patulitrin (a glucoside of petuletin), sitosterol (steroid), spicigerine (alkaloid), prosogerine $\mathrm{A}$ and $\mathrm{B}$, prosogerin $\mathrm{C}$ and prosogerin $\mathrm{E}$ (flavones) ${ }^{20}$.

The chemical structures of ellagic acid, $\beta$-sitosterel and lycopene are shown in Figs. 1-3.<smiles>O=c1oc2c(O)c(O)cc3c(=O)oc4c(O)c(O)cc1c4c23</smiles>

Fig. 1. Chemical structure of elagic acid<smiles>CCC(CC[C@H](C)[C@H]1CC[C@H]2[C@@H]3CC=C4CC(O)CCC4(C)[C@H]3CC[C@]21C)C(C)C</smiles>

Fig. 2. Chemical structure of $\beta$-sitosterol

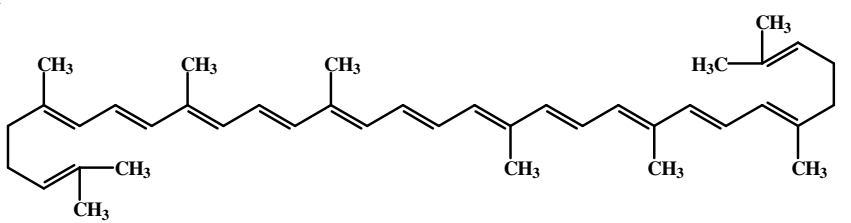

Fig. 3. Chemical structure of lycopene

\section{EXPERIMENTAL}

1,1-Diphenyl-2-picrylhydrazyl (Sigma Germany), ethanol and methanol (Merck KGaA Darmstadt, Germany), acetone (BDH England) and $n$-hexane (Franken Chemicals, Germany), hydrochloric acid, $\mathrm{Na}_{2} \mathrm{SO}_{4}$ (Merck, Germany), distilled water Department of Pharmacy, IUB, Pakistan were chemical used in this study. Elisa Plate Reader (Biotek Synergy HT), Electrical Balance (Precisa BJ-210, Switzerland), Refrigerator Dawlance, Pakistan), Rotary evaporator (Eyela, Co. Ltd. Japan), ultraviolet (UV) Spectrophotometer (Shimadzu Japan), micropipettes, separating funnel, water bath (HH.S S14 $_{2}$, China). Maceration and hot percolation methods were used in extraction process.

Punica granatum, red and white was collected from local market of Bahawalpur, Pakistan and peel dried at room temperature for 5 weeks. Lycopersicon esculentum, red and green was collected in fresh form from local market. The identification of the plant (Punica granatum) was performed at the Cholistan Institute of Desert Studies (CIDS), The Islamia University of Bahawalpur, Pakistan. Carica papaya, red and yellow were collected from Metro market Lahore. The identification of the plant (Carica papaya and Lycopersicon esculentum) was performed at the Institute of Horticultural Sciences, the University of Agriculture, Faisalabad, Pakistan (Papaya, Voucher No. 70512- 1907), (Punica granatum, Voucher No. 22007-9-1886), Lycopersicon esculentum (419-6-1934). Herbarium Department of Botany, Faisalabad University).

\section{Extraction methods}

Punica granatum extract: $100 \mathrm{~g}$ shade-dried ground plant material for each sample of red and pale Punica granatum fruit rinds were extracted three times, with $50 \%$ aqueous ethyl alcohol, at $60-70^{\circ} \mathrm{C}$ for $2 \mathrm{~h}$. The extracts residue was removed 
by filtration through 16th layers of muslin cloth. The ethyl alcohol was removed under vacuum. The resulting aqueous solution was acidized with hydrochloric acid and then refluxed at $70{ }^{\circ} \mathrm{C}$ for $6 \mathrm{~h}$. The concentrated extract was collected by rotary evaporator and then was filtered through Whatman No. 1 filter paper. The extract was stored at refrigerator.

Lycopersicon esculentum extract: $100 \mathrm{~g}$ material of each red and greenish Lycopersicon esculentum pulp was extracted with hexane-ethanol-acetone (50:25:25). After extraction, 15 $\mathrm{mL}$ of water was added to separate the solution into polar and no polar layers. Mostly carotenoids and Lycopene was concentrated in the upper non polar phase while other components and polar pigments will contain in the lower polar phase. Both layers were separated by separating funnel. Polar phase were collected and concentrated at rotary evaporator. Concentrated extract was filtered through Whatman No. 1 filter paper and stored extract in amber coloured bottles in refrigerator.

Carica papaya extract: $100 \mathrm{~g}$ of red and yellow Carica papaya fruit pulp slurry was weighted and quantitatively transferred to test tube with about $200 \mathrm{~mL}$ of a ethanol: hexane 1:1 solvent mixture and homogenized in a blender. All pulp residue retain was transfer to test tube, by repeating homogenization process, addition of $200 \mathrm{~mL}$ methanol: hexane 1:1 and filtration running until papaya pulp lose its typical colour completely almost three times. All filtrate material was transferred to a separator funnel added by $200 \mathrm{~mL}$ hexane and $250 \mathrm{~mL}$ distilled water and then was shake lightly for 30-60 s and left to rest for phase separation, collecting hexane phases containing all the carotenoids substances. Aqueous residue will removed from hexane phase by adding $1.0 \mathrm{~g}$ of anhydrous sodium sulphate and then shake manually for $30 \mathrm{~s}$. All hexane carotenoids extract content was removed to $2 \mathrm{~L}$ beaker and concentrated by vacuum rotary evaporator at about $40{ }^{\circ} \mathrm{C}$, for $25 \mathrm{~min}$. After concentration, samples were recovered in hexane and then transferred to brown colour bottles and the exact volume completed with hexane.

A summary of extraction solvents of six different varieties of these three plants are given in Table- 1 .

\begin{tabular}{lcc}
\multicolumn{3}{c}{ TABLE-1 } \\
\multicolumn{1}{c}{ PLANT PARTS AND SUITABLE SOLVENTS } \\
\hline \multicolumn{1}{c}{ Plants } & Solvents & $\begin{array}{c}\text { Solvents } \\
\text { ratios }\end{array}$ \\
\hline Red pulp tomato & Hexane:ethanol:acetone & $2: 1: 1$ \\
Red pulp papaya & Hexane:ethanol:methanol & $1: 1: 1$ \\
Red Pomegranate rind or peel & Ethanol:water & $1: 1$ \\
Greenish pulp tomato & Hexane:ethanol:acetone & $2: 1: 1$ \\
Yellow pulp papaya & Hexane:ethanol:methanol & $1: 1: 1$ \\
White pomegranate peel & Ethanol:water & $1: 1$ \\
\hline
\end{tabular}

Preparation of DPPH reagent: 1,1-Diphenyl-2-picrylhydrazyl (DPPH) was prepared by taking $1 \mathrm{mg}$ of DPPH in $25 \mathrm{~mL}$ methanol to make $100 \mu \mathrm{m}$ solution.

DPPH radical scavenging activity: The stable DPPH radical was used for the determination of antioxidant activity. Different concentrations of extracts in respective solvents were added at an equal volume of $10-90 \mu \mathrm{L}$ of $100 \mu \mathrm{M}$ methanolic DPPH soln. in a total volume of $100 \mu \mathrm{L}$ in 96 well plates. The contents were mixed and incubated at $37^{\circ} \mathrm{C}$ for $0.5 \mathrm{~h}$. Ascorbic acid was used as standard antioxidant. The reduction in absorbance was measured at $517 \mathrm{~nm}$ by using microplate reader; in comparison with the control solution (maximum absorption) the decrease in absorbance indicates increased scavenging activity. The activity is mentioned in percentage form of DPPH radical scavenging according to the following formula:

Inhibition $(\%)=\frac{(\text { Absorbance of control }- \text { Absorbance of test })}{\text { Absorbance of control }}$

DPPH radical scavenging activity was measured in triplicate.

Investigation of secondary metabolites: The different chemical tests were performed on the six different varieties of three plants which were Punica granatum (red and white), Carica papaya (red and yellow) and Lycopersicon esculentum (greenish and red), extracts of to screen for various classes of bioactive secondary metabolites such as alkaloids, saponins, tannins, flavonoids, ellgitannins, anthraquinones and carotenoids according to the standard method methods.

\section{RESULTS AND DISCUSSION}

Antioxidant activity: The DPPH scavenging activity of various plants extracts are shown in Table-2. Various plants have different free radical antioxidant activity depend upon different constituents. The Punica granatum extract, $50 \%$ ethyl alcohol w/v peel extract showed $84 \%$ DPPH scavenging activity with ascorbic acid standard. However, the percentage inhibition of Lycopersicon esculentum and Carica papaya extracts were 79 and $73 \%$, respectively and also measured antioxidant activity of extracts of greenish pulp tomatoes, yellow pulp papaya and white pomegranate extract when ascorbic acid was used as a standard.

\begin{tabular}{|c|c|c|c|}
\hline \multicolumn{4}{|c|}{$\begin{array}{c}\text { TABLE-2 } \\
\text { DPPH RADICAL SCAVENGING ACTIVITY } \\
\text { FOR VARIOUS PLANTS EXTRACTS }\end{array}$} \\
\hline Plant extracts & $\begin{array}{l}\text { Activity } \\
(\%)\end{array}$ & Plant extracts & $\begin{array}{c}\text { Activity } \\
(\%)\end{array}$ \\
\hline $\begin{array}{l}\text { Red pulp tomato } \\
\text { extract }\end{array}$ & 79 & $\begin{array}{c}\text { Greenish pulp tomato } \\
\text { extract }\end{array}$ & 61 \\
\hline $\begin{array}{c}\text { Red pulp papaya } \\
\text { extract }\end{array}$ & 73 & $\begin{array}{c}\text { Yellow pulp papaya } \\
\text { extract }\end{array}$ & 53 \\
\hline $\begin{array}{c}\text { Red pomegranate peel } \\
\text { extract }\end{array}$ & 84 & $\begin{array}{l}\text { White pomegranate } \\
\text { peel extract }\end{array}$ & 58 \\
\hline
\end{tabular}

Red pomegranate is rich source of phenolic compounds and important source of anthocynins. Pomegranate rind is rich in ellgitannins; gallotannins and ellagitannins are also found in various plants and hydrolyzed in ellagic acid upon acidic conditions. Rind extract containing $90 \%$ ellagic acid was test for skin whitening effect but when activity compared with white peel or rind pomegranate extract which have low activity due to contents composition. Ellagic acid has been found anticarcinogenic, antifibrosis and antioxidant properties. $n$ Hexane extracts of papaya and tomatoes pulps showed 79 and $73 \%$ free radical scavenging activity but low antioxidant activity of yellow pulp papaya and greenish pulp tomato extracts $^{21}$. Carotenoids like $\beta$-carotene and lycopene act as powerful antioxidant which gives red colour to tomatoes. Lycopene absorbs radiation at long wavelength at visible 
spectrum. Tomatoes extract which contain lycopene and carotenoid is useful for sunburn, in cosmetic composition for renewal and regeneration of skin and increase the thickness of epidermis.

Tomatoes are the major source of antioxidant such as carotenoids, lycopene and ascorbic acid which are considered an important source of this compound in the human diet. 72$92 \%$ lycopene was found as a water insoluble fraction. The tomatoes and tomato products in preventing cardiovascular disease and protecting against some types of cancer (based on lycopene content) as well as against ultraviolet light-induced erythema.

The red fleshed papaya is rich source of carotenoid and lycopene which is potent antioxidant which is beneficial for cardiovascular, cancer and against oxidative damage. Antioxidants are not only beneficial for humans and animal but also protect plants.

Phytochemical evaluation: Preliminary phytochemical analysis reveals that the crude extract of these varieties of plant contains alkaloids, flavonoids, saponins, carotenoids and ellgitannins as shown in Table-3.

\begin{tabular}{cccc}
\multicolumn{4}{c}{ TABLE-3 } \\
\multicolumn{4}{c}{ RESULTS OF PHYTOCHEMICAL ANALYSIS } \\
\hline $\begin{array}{c}\text { Phytochemical } \\
\text { tests }\end{array}$ & $\begin{array}{c}\text { Test } \\
\text { results }\end{array}$ & $\begin{array}{c}\text { Phytochemical } \\
\text { tests }\end{array}$ & $\begin{array}{c}\text { Test } \\
\text { results }\end{array}$ \\
\hline Alkaloids & ++ & Carotenoids & ++ \\
Saponins & + & Anthraquinones & ++++ \\
Flavonoids & ++ & Ellgitannins & +++ \\
\hline
\end{tabular}

Plants produce a wide variety and high diversity of secondary metabolites, which are not needed for primary or energy metabolism. They are not useless waste compounds, however, as previously assumed, but important for the ecological fitness of a plant producing them. Secondary metabolites have apparently evolved as a means for plants to protect themselves against insects, mammals and other herbivores, against bacteria, fungi, viruses and even other competing plants. Some plants use secondary metabolites in addition to attract pollinating and seed dispersing animals or for UV protection. Plants usually synthesize, transport and store secondary metabolites in a specific and particular way.

\section{Conclusion}

It was concluded that $50 \%$ ethyl alcohol w/v peel extract of Punica granatum extract showed maximum free radical scavenging activity. The $50 \%$ ethyl alcohol w/v is the best solvent for obtaining the antioxidant activity of Punica granatum. So we choose the plant that will be the best for further use in different beneficial formulations for human like cosmetics formulations, whitening agents, antiaging effects and pharmacological formulation development. The results also reviled that six different varieties of three different plants which were Punica granatum (red and white), Carica papaya (red and yellow) and Lycopersicon esculentum (greenish and red), extracts in different solvents contains active biological constituents. Therefore further evaluation directs to isolation of responsible components which will provide new lead compounds in future.

\section{ACKNOWLEDGEMENTS}

The authors thank The Chairman/Supervisor Prof. Dr. Naveed Akhtar, Faculty of Pharmacy and Alternative Medicine, The Islamia University of Bahawalpur for their constant encouragement and moral support. The authors also acknowledged the Higher Education Commission for providing the financial support to this study.

\section{REFERENCES}

1. C. Kaur and H.C. Kapoor, Int. J. Food Sci. Technol., 36, 703 (2001).

2. M. Aviram, L. Dornfeld, M. Rosenblat, N. Volkova, M. Kaplan, R. Coleman, T. Hayek, D. Presser and B. Fuhrman, Am. J. Clin. Nutr., 71, 1062 (2000).

3. F. Afaq, A. Malik, D. Syed, D. Maes, M.S. Matsui and H. Mukhtar, Photochem. Photobiol., 81, 38 (2005).

4. W. Zhu and J. Gao, J. Invest. Dermatol. Symp. Proceed., 13, 20 (2008).

5. A.P. Kulkarni and S.M. Aradhya, Food Chem., 93, 319 (2005).

6. N.S. Deeba, A. Farrukh and M. Hasan, Seminars Cancer Biol., 17, 377 Published by Elsevier Ltd (2007).

7. L.S. Baumann, Dermatologic Ther., 20, 330 (2007).

8. M.J. Periago, F. Rincón, M.D. Agüera and G. Ros, J. Agric. Food Chem., 52, 5796 (2004).

9. R.K. Toor, C.E. Lister and G.P. Savage, Int. J. Food Sci. Nutr., 60, 119 (2009).

10. P.M. Choksi and V.Y. Joshi, Int. J. Food Prop., 10, 289 (2007).

11. R.K. Toor, C.E. Lister and G.P. Savage, Int. J. Food Sci. Nutr., 56, 597 (2005).

12. W. Stahl, U. Heinrich, S. Wiseman, O. Eichler, H. Sies and H. Tronnier, J. Nutr., 131, 1449 (2001).

13. L.C. Devitt, K. Fanning, R.G. Dietzgen and T.A. Holton, J. Exp. Bot., 61, 33 (2010)

14. S. Gurung and N. Skalko-Basnet, J. Ethnopharmacol., 121, 338 (2009).

15. Z.D. Draelos, Clin. Dermatol., 19, 474 (2001).

16. A. Khan, M. Rahman and M. Islam, Turk. J. Biol., 32, 37 (2008).

17. M.D. Ukani, N.B. Limbani and N.K. Mehta, Anc. Sci. Life, 20, 58 (2000).

18. P. Singh, B. Rani, A.K. Chauhan and R. Maheshwari, Int. Res. J. Pharm., 3, 46 (2012).

19. N.L. Rozzi, R.K. Singh, R.A. Vierling and B.A. Watkins, J. Agric. Food Chem., 56, 2638 (2002).

20. U.G. Chandrika, E.R. Jansz, S.M.D.N. Wrikamasinghe and N.D. Warnasuriya, J. Nath. Sci. Foundation Sri Lanka, 31, 237 (2004).

21. H. Schäfer and M. Wink, Biotechnol. J., 4, 1684 (2009). 